\title{
INFLACIÓN Y CANASTA BÁSICA
}

\section{MAYO - A90010 2014}

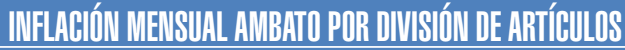

\begin{tabular}{|c|c|c|c|c|}
\hline TARARADIES & maly-14 & jun-14 & jull-14 & agg-14 \\
\hline GENERAL & -0.50 & 0.34 & 0.13 & 1.01 \\
\hline ALIMENTOS Y BEBIDAS NO ALCOHÓLICAS & -2.95 & 0.28 & 0.06 & 3.28 \\
\hline BEBIDAS ALCOHÓLICAS, TABACO Y ESTUPEFACIENTES & 0.94 & 0.46 & -0.54 & 0.02 \\
\hline PRENDAS DE VESTIR Y CALZADO & 0.08 & -0.48 & 0.24 & 0.39 \\
\hline ALOJAMIENTO, AGUA, ELECTRICIDAD, GAS Y OTROS COMBUSTIBLES & 1.75 & 1.99 & 0.07 & 0.17 \\
\hline MUEBLES, ARTÍCULOS PARA EL HOGAR Y PARA LA CONSERVACIÓN ORDINARIA DEL HOGAR & 0.40 & 0.04 & 0.21 & -2.20 \\
\hline SALUD & 0.47 & 0.04 & 0.05 & 1.87 \\
\hline TRANSPORTE & 0.35 & 0.94 & 0.30 & -0.04 \\
\hline COMUNICACIONES & 0.00 & -0.05 & 0.00 & 0.04 \\
\hline RECREACIÓN Y CULTURA & -0.02 & -0.40 & 0.71 & 0.60 \\
\hline EDUCACIÓN & 0.00 & 0.00 & 0.00 & 0.00 \\
\hline RESTAURANTES Y HOTELES & 0.73 & 0.43 & -0.07 & 0.43 \\
\hline BIENES Y SERVICIOS DIVERSOS & 0.78 & 0.09 & 0.24 & 0.14 \\
\hline
\end{tabular}

Fuente: INEC, Reporte Inflación Mayo-Agosto 2014

Elaboración: Equipo Técnico OBEST

INFLACIÓN NACIONAL, REGION SIERRA, AMBATO MAYO - AGOSTO 2014

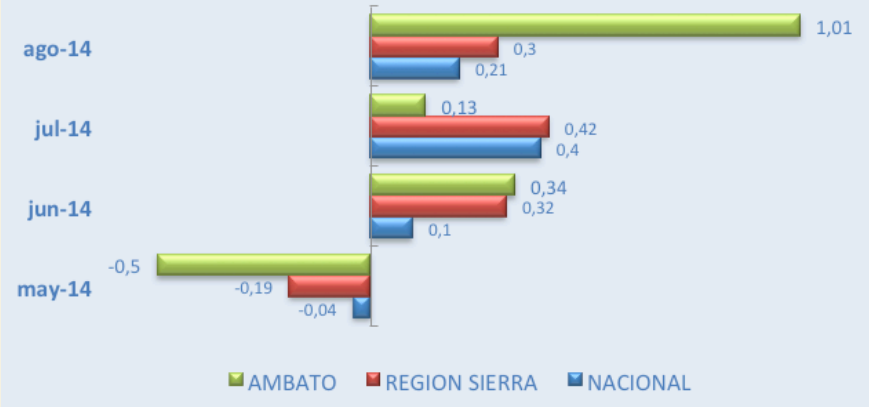

Fuente: INEC, Reporte Inflación Mayo-Agosto 2014 Elaboración: Equipo Técnico OBEST
La inflación mensual en los meses de mayo, junio, julio y agosto a nivel nacional fue de $-0.04 \%, 0.1 \%, 0.4 \%, 0.21 \%$ respectivamente.

La región sierra obtuvo variaciones mensuales de $-0.19 \%$, $0.32 \%, 0.42 \%, 0.30 \%$, mientras que en Ambato el comportamiento de la inflación fue el siguiente: en mayo $-0.5 \%$, junio $0.34 \%$, julio $0.13 \%$ y agosto $1.01 \%$

Los artículos que forman parte de las divisiones Recreación y Cultura $0.7 \%$; transporte $0.30 \%$ y prendas de vestir, calzado y bienes y servicios diversos con $0.24 \%$ son las que contribuyeron al incremento del índice general de precios IPC en el mes de julio, de igual manera se puede realizar el análisis de los meses de mayo y junio. 


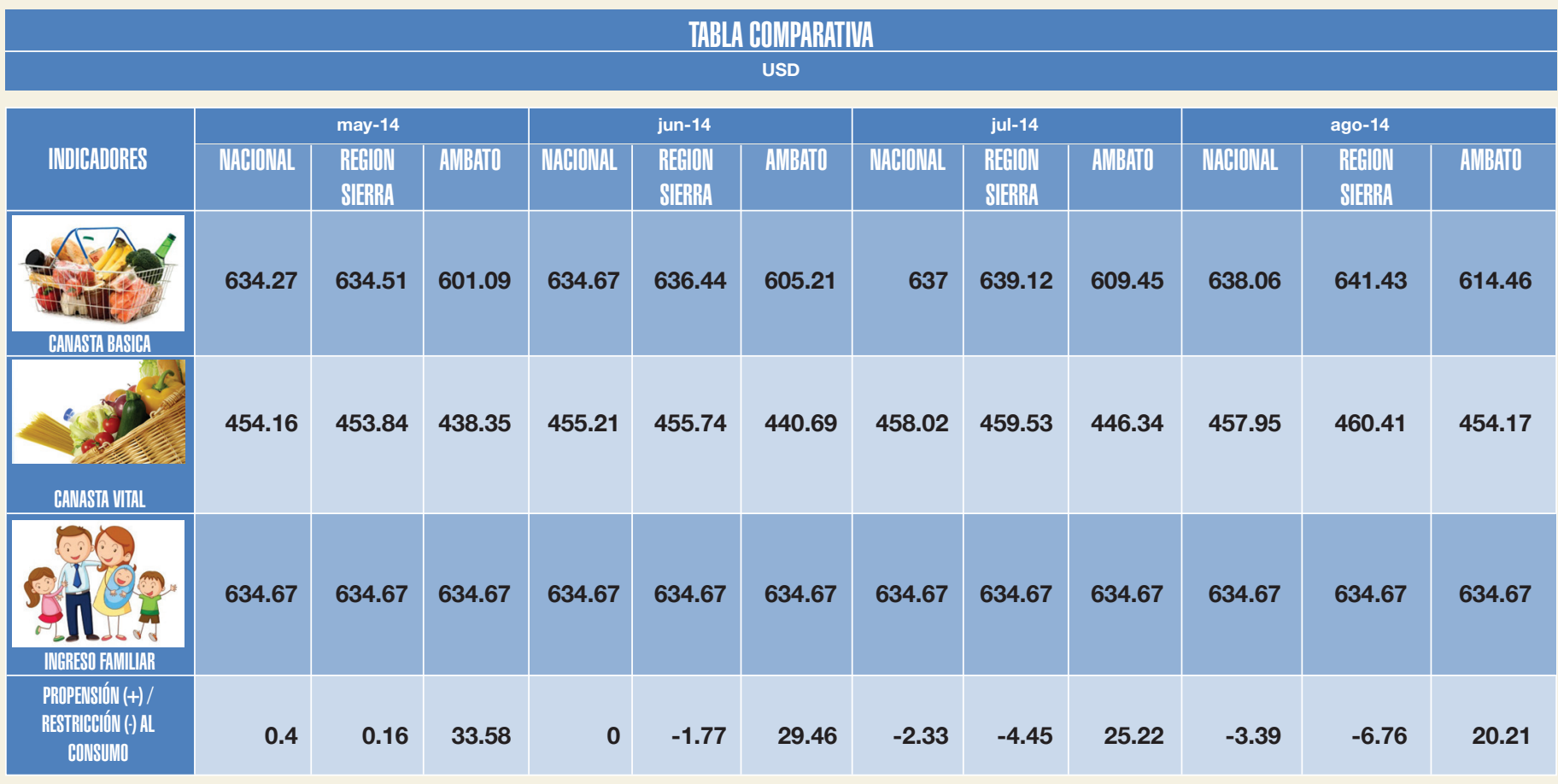

Fuente: INEC, Reporte Inflación Mayo-Agosto 2014

Elaboración: Equipo Técnico OBEST

\section{RESTRICCIÓN AL CONSUMO EN AMBATO MAYO - AGOSTO 2014 \\ USD}

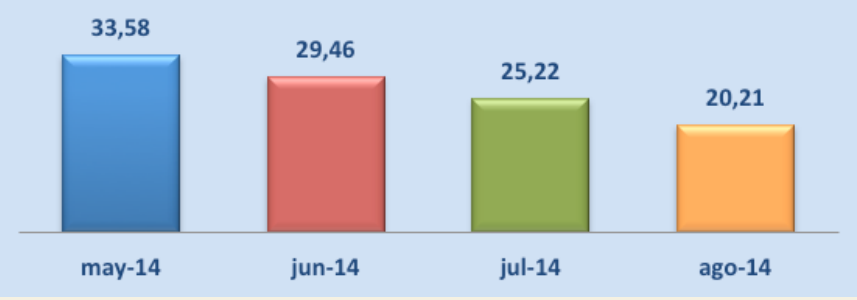

Fuente: INEC, Reporte Inflación Mayo-Agosto 2014 Elaboración: Equipo Técnico OBEST

En la tabla comparativa se determina que, en Ambato la canasta básica y vital ha disminuido con respecto a las canastas a nivel nacional y región sierra, el valor de la canasta familiar básica es 614.46 USD y la canasta vital es 454.17 USD en agosto de igual manera se puede comparar los meses de mayo, junio y julio.
Los ambateños en base a los ingresos de las familias durante los meses de mayo, junio, julio y agosto tuvieron propensión al consumo de 33.58 USD, 29.46 USD, 25.22 USD; y, 20.21 USD respectivamente.

Mientras que la región sierra tuvo propensión al consumo en mayo 0.16 ctvs., y restricción en junio 1.17 USD, julio 4.45 USD y agosto 6.76 USD.

A nivel Nacional se tuvo propensión al consumo de 0.4 ctvs., en el mes de mayo, en junio se determina que los ingresos de las familias cubren el costo total de la canasta básica, en julio y agosto hay restricción al consumo de 2.33 USD. y 3.39 USD, lo que significa que cubrió el $99.63 \%$ y $99.47 \%$ del costo de la canasta básica respectivamente.

\section{Observatorio Económico y Social de Tungurahua (OBEST) -} Universidad Técnica de Ambato.

Econ. Tatiana Vayas

Lic. Sandra Garcés

Fuente: INEC, reporte inflación mayo, junio, julio y agosto 2014 